U.S. Bureau of the Census. (1992). General Population Characteristics, Nebraska. Washington, D.C.: U.S. Govemment Printing Office.

U.S. Department of Commerce. (1991). Census Bureau Releases. 1990 Decennial Counts for Persons Enumerated in Emergency Shelters and Observed on Streets. (press release CB91-117) Washington, D.C.: Bureau of the Census.

\section{FEMINIST CROSS-CULTURAL RESEARCH: OBSERVATIONS FROM A RESEARCH PROJECT IN GERMANY*}

\author{
MARINA A. ADLER \\ University of Maryland Baltimore County \\ MARS/Social Thought \& Research, 1997, Vol. 20, No. 1-2.
}

Recent research indicates that the rapid imposition of West German structures (policy, economy, culture) on East Germany caused economic bardships and personal insecurities which leave many East German women feeling vulnerable. This essay depicts the experiences involved in conducting an ethnographic study to examine the situation of women East and West of the former German border. Secondary analysis, survey research, observation and interviews with women's representatives show significant differences in the actual and perceived consequences of unification for women's lives in East and West. The feminist nature of the research and the complex structure of German bureaucracy were often impediments to the progress of this study. Recommeñdations for researchers planning to do cross-national studies on women are discussed.

\section{Introduction}

According to Shulamit Reinharz (1992, p. 109) "cross-cultural research requires cooperative local political conditions that may be tenuous if studies concern women." Hence, the success of feminist research often depends on the degree of institutional cooperation in making information accessible to the researcher. Feminist research generally involves the following features: (a) the researcher is a selfidentified and outspoken feminist; (b) the research is not only about women but for women; (c) the objective of the research is social change;

- An earlier version of this paper was presented at the Panel Session "Doing Research in Other Countries: Insider and Outsider Perspectives," at the Southern Sociological Society's Annual Meetings, April 9, 1994 in Raleigh, North Carolina. Thanks for comments on the paper go to April Brayfield and Stephen Blackwelder. This research was partially supported by ASA/NSF and the University of Maryland Baltimore County. Department of Sociology, Baltimore, MD, 21250 
and (d) thereby challenges the status quo, patriarchal institutions, and the assumptions of male-centered thinking (see Reinharz 1992). This essay applies these insights to my study of women's lives in rural, very traditional areas of Germany after unification. Not only did its exclusive focus on women become cause of concern among some of the local officials, but my identity as social scientist seemed to be "overridden" by my membership in the group to be studied. Thus, my advocacy for the empowerment of women "clashed" with my status as professor because my policy recommendations could "threaten the established order". Two of the assumptions guiding cross-cultural research, namely the significance of cultural specificity and the necessity. of intensive examination (Reinharz 1992), were of particular importance to choosing the methodology for this research project. The purpose of my study was to explore the changes in women's opportunities resulting from the transformation of the economic, social and cultural structures in unified Germany. In addition, I hoped to evaluate current social policy in light of the fact that in the former German Democratic Republic (GDR) the state supported caregiving employed women, while Federal Republic of Germany (FRG) policies support homemaker-mothers. In order to be sensitive to the complexities of the issues inherent in identifying actual and perceived changes in the everyday lives of women in addition to structural changes, I chose an ethnographic approach. According to Reinharz (1992, p. 46) "contemporary ethnography or field work is multimethod research. It usually includes observation, participation, archival analysis, and interviewing, thus combining the assets and weaknesses of each method."

I will first describe the research context and goals of my study, followed by a narrative of my experiences while doing research in Germany in the summers of 1993, 1994 and 1996, including some of the major research findings (see also Adler forthcoming). The focus is mainly on methodological insights gained from interacting with the women in the study in order to share ideas about the research process with researchers intending to study women in a cross-cultural setting.

\section{The Research Context}

On October 3, 1990, the official date of German reunification, East Germany was incorporated into West Germany. Unification increased the political rights of former GDR citizens, such as the freedom of speech, free elections, the end of political persecution, and the right to travel freely (Beyer 1992; Gerhard 1992; Goldberg, 1991). Among the negative consequences were reduced social benefits for the average East German family, loss of economic independence and reproductive freedom for women (Kolinsky 1992; 1993), and the subordination of
Research in Germany

East German values to West German culture. The collapse of the economy and of the infra-structure of social services in the East have created high unemployment, which has hit women disproportionately hard (Adler 1997; Beyer 1992; Einhorn 1992; Gerhard 1992; Marvin 1995; Sheffer-Hegel 1992). In fact, many women in the new states (East Germany) are facing poverty and the struggle for economic survival for the first time. In addition, and more unexpectedly, traditional West German norms and values about gender roles and women's employment leave many East German women feeling vulnerable.

Given this new era of personal insecurities, I expected that East German women have fewer opportunities and are more pessimistic about the changes produced by unification than West German women. Hence the research questions for this study were about the objective and perceived consequences of these changes for women's lives. Secondary analysis of published and unpublished sources (recent newspaper articles, journals, and statistics), survey research (mailed questionnaires), observation, as well as interviews with women's representatives and activists (including focus groups) were employed to examine how women in Germany cope with changes in their lives and their opportunities.

\section{Data Collection In Germany}

I approached this exploratory research from the "many questions and few resources" angle. In order to use several different methods (triangulation) to answer my questions, I had to take advantage of as many connections on both sides of the Atlantic as possible. Small summer research grants from American Sociological Association and the University of Maryland covered basic travel expenses, duplication and mailing costs, and a local part-time assistant.

I recommend thorough "anticipatory trouble-shooting" before entering the host country. Thus, a list of potential problems and possible solutions with information on laws about privacy of information, rules about accessing data and addresses, and on local costs for materials, transportation and services should be compiled before leaving the U.S. Access to the Internet should make planning much easier. In considering the time frame for research abroad, it is useful to double the time it would take in the U.S.

Networking, i.e. establishing contacts, both professional and personal, is essential and has to be undertaken very early before entering the host country. Possible sources of contacts are international computer networks, colleagues in the home country, and university listings for the host country. Contact to researchers in the host country who have 
actually done similar research is invaluable as a source of information and advice. I asked my contact, a journalist and founder of a women's archive in the Western research area, to locate possible women's representatives for interviews months before I left the U.S. Information about the contact persons' schedules and availability during your research period has to be ascertained early, and appointments should be made long-distance in advance. Taking advantage of personal connections, such as relatives and friends keeps travel costs down, and enlisting their help in identifying respondents and their knowledge of local conditions, can be very beneficial.

The data for this exploratory study of predominantly rural areas East (the surrounding villages of Gotha and Dresden) and West (the surrounding villages of Hanau) of the former border come from various sources. In order to explore women's opportunity structure in these areas, I reviewed recent articles in regional newspapers and scholarly joumals, as well as statistics in official and unpublished documents. A West German women's archive gave me access to organized materials on local and national women's issues in recent years. The archive was established, with communal support, by a well-known retired journalist, whose connections to incumbent politicians and bureaucrats proved invaluable to this research

My field work involved visits to various major local employers as a means of assessing the employment opportunities for women. Attendance of meetings of local women's groups (participant observation) served to gain an understanding of the problems identified by local women. The members of the groups present at the meetings included a cross-section of women from all walks of life: farm women, midwives, village representatives, city and county women's representatives, union officials and activists. Nevertheless, their assessment of women's status in the new Germany was astonishingly similar. In the Eastern focus group sessions, women were eloquent in their analysis of the "fragmentation" of women's lives, and their preoccupation with economic survival rather than advancement of collective goals of the women's movement. They generally regarded me not as an outsider, but as an ally with a possible voice in documenting some of the problems they experience.

In addition, I interviewed various women whom I had identified as "experts," on the situation of women since unification. Eight women's representatives in local, state and city governments, unions, health organizations, and employment offices and $3 \mathrm{farm}$ women were interviewed in the West, and 12 women's representatives and 2 farm women in the East. The interviews included questions about
Research in Germany

respondents' job responsibilities, their experiences in working with women, and their perceptions of the impact of unification on women's lives in general and their own lives in particular. In general, the women were appreciative of my interest in their work and very cooperative. One Eastern women's bureau representative, however, was reluctant to share her assessment of the situation for fear of misrepresentation and misuse of the data. She explained that previous encounters with Western researchers had left her doubtful of their ethics. In addition, one West German company posed an interesting challenge by insisting that the union boss, who was male, be present for the interview with the women's employment representative. The reason was to ensure an "accurate" portrayal of the company's policies. This condition biased the women's representative's answers to the point that before answering, she would first turn to her boss and then concur with his statements.

The questionnaire was mailed to random samples selected from the residential register of the communities in the study areas. The survey included standardized questions regarding women's perceptions of their lives as changed by unification, including their ability to work outside the home, available educational and training opportunities, their ability to integrate work and family, and their future prospects/plans. In addition, the survey solicited information on their work history, educational, occupational and demographic characteristics, and amount of decisionmaking at work (work tasks) and at home (sense of control). Questions about income, work experience, and hours were also included. Due to the exploratory nature of the research, neither incentives for participation nor follow-up letters were used, which reduced the response rate to only about $22 \%$. The final sample included 43 West German and 41 East German women.

Many of the logistical problems I encountered during the data collection process were due to the German bureaucracy so aptly described by Max Weber. Although my having grown to adulthood in Germany gave me an advantage in language and cultural understanding, my lack of experience in actually doing research in Germany found me unaware of the obstacles posed by rigid bureaucratic structures. It seemed that every clerical task took much longer in Germany than in the U.S., mainly because office and store opening hours are short and precarious (i.e., nonstandardized). Although the official rationale for restricted business hours is increased family time and is well-intentioned, these restrictions also increase stress levels for those attempting to integrate employment and family responsibilities (or to do research). It was also my misfortune to conduct research during the main vacation time in Hessen, which meant that many officials and respondents were gone for 6 weeks. Their replacements were often reluctant to make 
decisions about sharing information in the absence of their superiors. This strict adherence to the proper channels of command significantly delayed the progress of data collection. The original plan to bypass bureaucracy by obtaining addresses from voter registration data failed because voter information is protected under the right to privacy act. Using the community telephone directories was inappropriate because in Germany often only the "man of the house" is listed, and in the East many people still do not own telephones. In order to get addresses from the residential register, which is not protected by the privacy act, I had to justify the research purpose and convince the local govemors that it is "in the public interest". This fact was finally certified because of the extensive networking efforts of my journalist friend. Thus, it took weeks to get the required credentials and the appropriate forms and signatures, and to attain the governors' permission to request addresses from the various mayors' offices in the jurisdictions covered. After an additional 2 weeks we obtained the requested addresses, which were randomly selected by the assistants of the officials. Interestingly, the mayor of one Western community insisted on receiving $\$ 10$ per address, which prompted me to use the telephone book for this particular sample.

Some of these problems I encountered are probably characteristic of rural areas all over the world and seem quite trivial but can prove frustrating and time-consuming. Despite rumors to the contrary, the "information super highway" has bypassed much of rural Germany, particularly in the East. FAX and E-mail are not as common in Germany as they are in the U.S., and in the East even the telephone system is antiquated. Furthermore, the library system at German universities is not very user-friendly, and seems to be organized around impediments to that the reader has unlimited time resources. Other impediments to successful work arose from seemingly simple matters, such as differences in size standards for paper and envelopes, as well as cassette tapes for transcription machines, and electricity conversion. paper with Geraterials was not only costly, but to match American size a near impossibility. In addition and duplication machines for mailings was were quite difficult to follow: the postal rules regarding mass mailings and color rubber to follow: they involved the purchase of various size hours of manual labor.

\section{Feminist Research In Germany}

My dual status as German citizen and American resident seemed to make me "interesting" to respondents, and thus was useful in establishing rapport, generally facilitating my research efforts. Having grown up in the Westem study area with my family still living there, and having
Research in Germany

numerous relatives living in the study areas in East Germany also opened doors. I believe that the feminist nature of my research is responsible for some of the "less positive" reactions I encountered. While most of the women reacted very positively to me and my research endeavor, many respondents in both East and West wondered why I only collected data from women. Feminist research questions focusing exclusively on women rather than on a comparison of women to men, seem to be a novelty in the rural areas I studied. Yet the women's representatives on both sides of the border, whose jobs entailed familiarity with feminist issues, were extremely helpful in establishing essential connections, and readily assisted in acquiring data and information for me.

Some of the women, and many of the men I encountered, considered my status as a female, American professor as ambivalent. Several mayors (all were men) were quite uncooperative until articles about my research soliciting the cooperation of local residents appeared in major area newspapers, which seemed to legitimize my status. The pattern was different for my encounters with some of the female academics. Female professors are very rare in Germany. In fact, national statistics show that there are fewer female professors than female lawyers or physicians. Hence female social science professors have created a niche for themselves in women's studies. Their reluctance to meet with me (unanswered letters, ignored phone calls, and a general hesitation or refusal to assist in my research efforts) may be explained by (1) the perception of myself as an outsider, who may compete for scarce research resources; (2) the fact that due to their low numbers female academics also have particularly high demands made on their time; (3) previous negative encounters with Western researchers. Whatever the reason, this lack of cooperation among academic feminist researchers raises important questions for research collaboration crossing national boundaries. Women's representatives and activists in the "trenches" were eager to help because they are confronted daily with the various hardships faced by women, and thus seem to welcome increased research efforts aimed at improving the status quo.

\section{Some Research Results}

The findings of this research can be grouped along the lines of three themes (see Adler forthcoming): (1) widespread insecurity and fears about the future due to loss of independence in the East; (2) ambivalent feelings towards, and differing definitions of, feminism in East and West, (3) questions about the nature of women's liberation (Emanzipation) and equal rights (Gleicbberechtigung) under socialism and capitalism.

In addition to high unemployment rates, the unified German welfare 

state is generally shrinking the "safety net," and an increasing
feminization of poverty can be observed. Furthemore, divorce, formation and dissolution declining in the East, in part because family become "unaffordable" (see Adler, and babies seem to have rapidly East German autonomy. Since unification has increased personal safety and individual women in the East resuling increased crime and violence against first time (Einhorn 1992). Most toubling is women's mobility for the . Most troubling is the increased evidence of the increased visibility and arly wife battering. This trend is in part due to increase in incidencen ather than an shortages and complex divorce Nevertheless, substance abuse, housing more expensive and difficult laws (West German law makes divorce problem. Increased dependt than former GDR law) contribute to the women in the new Endence on relationships with men leaves many vulnerable, with very limited states feeling physically and financially trends have brought limited access to resources. In combination, these homeless shelters, services (substance abuse) shelters, runaway hotlines, mental health bureaus.

My interviews with the women's representatives reflected evidence for a lack of unity among women on both sides of the former border (see also Schaeffer-Hegel 1992). East German women expressed resentment about being treated by Westem women like unequal partners in the children" by West change. Their sentiments about being "talked to like as "the classic tanguage of echo what Bassnett $(1992$, p. 11) refers to 'discovers' a new land and finds colonizer, the parental figure who need to be civilized." This finds the natives to be childlike creatures who to mutual undized development of the ling and the exchange of ideas fundamental to the necessary to effect lind of strong women's movement which is "no paternalistic state, whether in. According to Beyer (1992, p. 113), legal framewor state, whether in the guise of state socialism or of the practical equality for women and men in take steps towards creating so." Given these women and men in daily life unless forced to do the East German women I found myself having to "prove myself" to observer and by clarifying by emphasizing my status as independent point of view.

Another barrier to research on women in rural Germany is inherent in the label "feminist." As Bassnett (1992) points out, different "feminisms" arise from varying historical, economic and cultural
Research in Germany

contexts. Similarly, patriarchy will take different forms and have varying consequences for women. Historically German women's everyday life experiences were shaped by socialist and capitalist patterns of patriarchy. Although some of the German patriarchal values are shared in the rural areas of the old and new states, definitions and expressions of feminism vary. My reception as "feminist researcher" in the West was colored by assumptions (and some negative stereotypes) about women's liberation based on the "cult of individualism" (Bassnett 1992), which focuses on raising individual women's consciousness. In the East, however, I was greeted with statements assigning "women's issues" lower priority than more immediate social problems, such as unemployment and crime, targeting collective well-being rather than special group concerns. Dependence on the GDR state has created less urgency for the Western "brand" of feminism, which was a reaction to dependency on men.

\section{Conclusion}

This narrative of the experiences involved in conducting research in the summer of 1993, 1994 and 1996 in Germany contains several lessons for future research endeavors in Germany. The various logistical problems served to enlighten me about doing research in less familiar territory and without access to accustomed resources. American researchers are clearly "spoiled" by easy access to research resources, communication technology, data, libraries, and computers. I will continue attempts to establish collaborative ventures with German academics by sharing my research findings and opening communication channels for a hopefully mutually beneficial exchange of ideas.

The manifest intention of this research was to understand the effects of German unification from the point of view of women's experiences. The latent agenda was to help erode the historical stigma on being an "Emanze" ("women's libber") by conveying a more accurate, positive, and constructive image of women-centered research. In order to do so I had to reflect on the struggles of East German women, whose lives have been very different from West German women's experiences over the past 2-3 generations. Like other Western feminists I had to resist the temptation to offer some sort of "recipe" solution modeled on my experiences. East German feminism has to evolve from its own needs, history and culture (see Bassnett 1992). In order to be useful in this process, Western researchers have to listen to the voices of women dealing directly with social change. In the case of Germany, this includes the unemployed, community leaders (women's representatives and activists), local researchers, and "ordinary" women.

In order to open more effective channels of communication among 


\section{MARS/Social Thought of Research}

women in the old and new states, any patronizing attitudes have to be discarded in favor of more constructive and less ethnocentric perspectives. The same holds for feminist researchers from different cultural origins. As Reinharz (1992, p. 121-22) observes, "unfortunately, current feminist cross-cultural research tends not to include much collaboration between scholars from the host society and from other societies," a fact which has "generated considerable divisiveness among feminists." I would like to extend the call for "internationalist perspectives" to one based on less formal boundaries, encouraging feminist researchers to embrace "doing difference" (see West and Fenstermaker 1995). The concept of "otherness" or "difference" of researcher and "subject" can enrich the framing of questions and methodology even within a given society, based on differences in race, culture, or lifestyle.

Assumptions of homogeneity and the quest for the identification of universal patterns of oppression may threaten our understanding of the diversity of experience among women. For example, the label "East German women" already includes a vast array of different experiences in the post-unification era. Some have managed to turn the economic chaos of monetary reform and pre-WWII ownership claims into an advantage by investing in and establishing businesses. Others were able to use the initial tide to move West as an opportunity to secure employment. The majority of women were less fortunate, however, and had to struggle to varying degrees. Here the lines between "universals" and "specifics" become blurred: although most struggled, the particular circumstances of that experience varied considerably. And within the various experiences, patterns crystallized, calling for "internal" modes of explanation in terms of the women's own perceptions. Cross-cultural research at its best should counteract generic Westem feminist thought, i.e. theory and methodology based on a Western (albeit often based on good intentions) points of view.

\section{References}

Adler, Marina A. 1997. "Social Change and Declines in Marriage and Fertility in Eastern Germany." Journal of Marriage and the Family 59:.

Adler, Marina A. forthcoming. "Impact of German Unification on Women in the Rural East and West." Sociological Focus

Bassnett, Susan. 1992. "Crossing cultural boundaries. Or how I became an expert on East European women ovemight." Women's Studies International Forum 15, 11-15.
1992 "The situation of East Gem Women's Studies International Forum 15

\section{1-114.}

1992. "Frauenerwerbsarbeit in den neuen und Anforderungen an Frauenpolitik - am Beispie Bundesl@ndem und Anforderungen an Frauentogischen Studie aus von empirischen Ergebren

Sachsen." Sozialwissenschaften und Berufspraxis 15:376-393.

Dahlerup, Drude. 1987. "Confusing Concepts-Confusing Reality: A Theoretical Discussion of the Patriarchal State," pp. 93-127 in Anne Showstack Sassoon (ed.) Women and the State: The Shifting Boundaries of Public and Private. London: Hutchinson.

Einhom, Barbara. 1992. "German Democratic Republic-Emancipated women or hardworking mothers." In Chris Corrin (ed.) Superwomen and the Double Burden (pp.125-154). Toronto, Canada:Second Story Press.

Gerhard, Ute. 1992. "German women and the social cost of unification." German Politics and Society 24\&25, 16-33.

Gertrude Schaffner. 1991. "Women on the verge: Winner (nocial Policy Fall, 34-44.

1992. "Women in the new Germany: The East-West

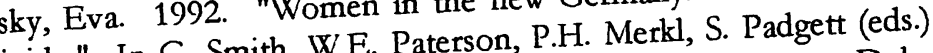
divide." In G. Smith, W. P. Patics (pp. 264-280) Durham: Duke Developments in German Politics (pp. 264-280) University Press.

Kolinsky, Eva. 1993. Women in contemporary Germany. Providence, RI: Berg Publ.

in Grace M 1995. "Two Steps Back and One Step Forward: East , Wall." Humanity of Society German

Nickel, Hildegard Maria. 1992. "Women in the German Democratic , Fooking Backwards and Forwards." German Politics and Society 24\&25:34-52.

Reinharz, Shulamit. 1992. Feminist methods in social research. Oxford University Press: New York.

Schaeffer-Hegel, Barbara. 1992. "Makers and victims of unification: 


\section{Section on Social Movements}

Spelman, Elizabeth V. 1988. Inessential Woman: Problems of Exclusion in Feminist Thought. Boston: Beacon Press.

West, Candace and Sarah Fenstermaker. 1995. "Doing Difference." Gender and Society 9:8-37.

\section{Editor's Introduction}

\author{
JACK WELLER \\ University of Kansas
}

MARS/Social Thought \& Research, 1997, Vol. 20, No. 1-2

It seems to me that for some time to come most questions about social movements will continue to be studied on a case by case basis. The four articles collected in this section are excellent examples of the art of studying a case to address questions about social movements.

Thomas W. Foster's "American Culture through Amish Eyes: An Anarchist Perspective" is an examination of the living anarchist traditions of the Amish. The lineage of the contemporary Amish extends back 470 years to the Anabaptist Movement which closely followed the German Protestant Reformation. Harshly persecuted by both Protestant and Catholic state authorities, Anabaptism survived in groups that came to be known as Mennonites, Hutterites and Amish (Hostetler 1993). ${ }^{1}$

Despite rapid population growth that outstrips land for farming and consequent serious economic dislocations, the Amish have a vital tradition. Foster shows that the persistence of Amish culture, however, is not the product of blind traditionalism. Value-rational choices repeatedly have been made by Amish individuals, families, congregations and districts about how the Amish way of life can effectively be carried on. Amish choices vary substantially at each of these levels (Kraybill 1994). ${ }^{2}$ The Amish tradition has divided into radiating branches, pressed

1The Hutterites and the Amish left Europe by quite different itineraries and with fascinating but substantially different adaptations. They are two of the more distinctive variant cultures in North America today (Hostetler and Huntington 1996; Hostetler 1993; Kraybill 1994). Both have become institutionally-complete flourishing ways of life which persist in tension and interdependence with the American mainstream.

2There is no central decision-making authority for the Amish as a whole and the Ordnung of Amish precepts and rules is an oral tradition rather than written scriptures (Kraybill 1994). 